\title{
Some Properties of Glutamate Dehydrogenase from the Marine Red Alga Gracilaria sordida (Harv.) W. Nelson
}

\author{
Matern S. P. Mtolera \\ Institute of Marine Sciences, University of Dar es Salaam, P.O. Box 668, Zanzibar, Tanzania
}

Key words: ammonia assimilation, glutamate dehydrogenase, GDH, Gracilaria sordida, red alga, enzyme activity

\begin{abstract}
Glutamate dehydrogenases (GDH, EC 1.4.1.2-4) catalyse the entry of ammonium into the organic cycle via amination of $\alpha$-ketoglutarate and its release via deamination of $L$ glutamate. NAD-GDH facilitates NAD-/NADP-dependent deamination while NADPH-GDH facilitates NADH-/NADPH-dependent amination reactions. In the study reported here, GDHs were extracted from the red alga Gracilaria sordida and purified 10- to 180-fold before examining their amination and deamination reaction properties. NAD-/NADP- and NADH-/ NADPH-dependent activities were the order of 11:1 and 1:1.8, respectively. The $\mathrm{pH}$ optima for amination and deamination were 8.2 and 8.4 under NADH- and NADPH- and 8.4 and 9 under NAD- and NADP- dependent activities, respectively. Whereas both NAD- and NADP-dependent deamination activities were activated by calcium ions $\left(\mathrm{Ca}^{2+}\right)$, only NADPH-dependent amination was activated. The $\mathrm{K}_{\mathrm{m}}$ values (in $\mathrm{mM}$ ) were 3.0-3.6 for ammonia, 2.0-3.3 for $\alpha$-ketoglutarate, 0.00286 for NADH, 0.0033 for NADPH), 1.7-2.1 for L-glutamate, 0.344 for NAD and 0.476 for NADP. It appears that the GDHs in G. sordida are dominated by NAD-dependent deamination enzyme and that in NADH-NADPH- dependent amination reactions, NADPH is more preferred. It is suggested that NAD-GDH's role in G. sordida could be as a catabolic shunt facilitating respiration. Anabolic functions could be assimilation of ammonia released during photorespiration and synthesis of $\mathrm{N}$-rich transport compounds.
\end{abstract}

\section{INTRODUCTION}

The inorganic nitrogen acquired by plants is converted to ammonia before being assimilated into organic molecules. Amination of $\alpha$ ketoglutarate to glutamic acid is the major route of ammonia assimilation in plants. This reversible reaction may be catalysed by (1) glutamate dehydrogenases (GDH) and (2) glutamine synthetase (GS)/ glutamate synthase (GOGAT). In the GS/ GOGAT route, ammonia is first incorporated into glutamine by the action of GS and subsequently into glutamic acid by GOGAT. The GS/ GOGAT route is a dominant pathway in higher plants (Lea \& Miflin, 2003). The major hindrance to the GDH involvement in the mentioned organisms is low affinity to ammonia. The reported $\mathrm{K}_{\mathrm{m}}$ (ammonia) for GDH are generally higher than $5 \mathrm{mM}$ while tissue concentration of ammonia is in the range close to $1.0 \mathrm{mM}$. At about $2 \mathrm{mM}$ ammonia concentration, chloroplasts are uncoupled (Lea \& Miflin, 2003).

Studies so far have yet to establish the dominant amination pathway in algae. In some microalgae, e.g. Cyanidium caladarium (Rigano et al., 1979), Anabaena cylindrica (Lawrie et al., 1976; Wolk et al., 1976) and Chlamydomonas reinhardii (Cullimore \& Sims, 1981a \& b) the GS/ GOGAT route appears to dominate ammonia assimilation. However, in others e.g. Chlorella

E-mail: mtolera@ims.udsm.ac.tz 
autotrophica GS/GOGAT appeared to be more active in the presence of nitrate-N and GDH took over when ammonia-N was supplied (Ahmad \& Hallebust, 1984). Among the macroalgae, the occurrence of GDH has been reported, e.g. in Ulva lactuca (Jacobi, 1957), Caulerpa simpliciuscula (Gayler \& Morgan, 1976), Bryopsis maxima (Nisizawa et al., 1978) and Porphyra yezoensis (Sato et al., 1975, 1984). In the kinetic studies, $\mathrm{NADH}$-mediated GDH with affinity of $40\left(\mathrm{~K}_{\mathrm{m}}\right.$ in $\mathrm{mM}$ ammonia) has been reported in Chlorella sorokiniana (Meredith et al., 1978) and a NADPHmediated GDH with $\mathrm{K}_{\mathrm{m}}$ of 68 (Gronostajski et al., 1978) and 18-41 have been reported in Chlorella pyrenoidosa (Shatlov \& Kretovich, 1977). NADPH-GDH with affinity as high as $0.7-0.4$ has been reported from Caulerpa simpliuscula (Gayler \& Morgan, 1976)

In this paper, some properties of GDH from the marine red macroalga Gracilaria sordida are reported. This information contributes to the knowledge base of amination and deamination pathways in algae.

\section{MATERIALS AND METHODS}

\section{Materials}

Gracilaria sordida (Harv.) W. Nelson was collected in Hanukau Harbour, New Zealand, in December 1983 and maintained in monoculture in cylinder systems as detailed in Lignell et al. (1987). Its growth rate per day during the pre-cultivation period was around $25 \%$ in natural seawater with salinity of $33 \%$ o, $\mathrm{NH}_{4} \mathrm{Cl}$ content of $820 \mu \mathrm{M}$, $\mathrm{NaH}_{2} \mathrm{PO}_{4}$ of $30 \mu \mathrm{M}$, inorganic carbon $2.5 \mathrm{mM}$, $\mathrm{pH} 7.8 \pm 0.1$, temperature $26 \pm 0.5^{\circ} \mathrm{C}$, and light intensity of $800 \mu$ mole photons $/ \mathrm{m}^{2} / \mathrm{s}$. Seawater was changed every 2 weeks. For enzyme extraction, epiphyte-free samples were used after rinsing with distilled water and mild centrifugation to get rid of excess salts and water, respectively. All the chemicals used were purchased from Sigma Chemicals Co.

\section{Extraction and partial purification}

Two hundred and two grammes (202 g) of the algal sample were pulverised in liquid nitrogen using a mortar and pestle. All the procedures thereafter were carried out at $0-5^{\circ} \mathrm{C}$ unless otherwise stated. Extraction was effected in $200 \mathrm{mM}$ Tris- $\mathrm{HCl}$ (pH 8.0) containing $14 \mathrm{mM}$ mercaptoethanol and 5\% (w/v) polyvinylpyrrolidone (PVP) for 30 minutes. The turbid red extract was filtered through four layers of cheesecloth and centrifuged at 10,000 g for 30 minutes.

\section{Purification by ammonium sulphate}

Saturated ammonia sulphate solution was added to the supernatant to give a final concentration of $40 \%$, the suspension was stirred for 30 minutes and centrifuged at $20,000 \mathrm{~g}$ for 30 minutes. The supernatant was adjusted to $60 \%$ saturation with ammonia sulphate solution. After stirring for 30 minutes the precipitate was removed by centrifuging at $25,000 \mathrm{~g}$ for 30 minutes. As the precipitate had some enzyme activity, it was homogenised in the extraction buffer (without PVP) and re-extracted for 30 minutes while adjusted at $60 \%$ saturation with ammonia sulphate solution and treated as above to obtain the supernatant. The combined supernatant was finally adjusted to $75 \%$ saturation with ammonia sulphate solution, stirred for 30 minutes and the precipitate was obtained by centrifuging at 25,000 $\mathrm{g}$ for an hour. The precipitate was dissolved in the extraction buffer (without PVP) and dialysed in $10 \mathrm{mM}$ Tris- $\mathrm{HCl}$ ( $\mathrm{pH} \mathrm{7.4)} \mathrm{containing} 14 \mathrm{mM}$ mercaptoethanol for 12 hours and used for enzyme analysis.

\section{Purification by affinity precipitation and filtration by Centricon $\mathbf{3 0}$}

Affinity precipitation was achieved by using $\mathrm{N}_{2} \mathrm{~N}_{2}-$ adipodihydrazido-bis-( $\mathrm{N}^{6}$-carbonylmethyl-NAD) (Bis-NAD) as detailed in Flygare et al. (1983). The resultant precipitate was dissolved by addition of $0.5 \mathrm{ml}$ of $5 \mathrm{mM} \mathrm{NADH}$ and $1 \mathrm{ml}$ of $20 \mathrm{mM} \alpha-$ ketoglutarate. Centriprep 10 (with molecular weight cutoff point (MWCO) of 10,000) was used to remove Bis NAD and excess NADH and glutarate. Finally filtration using Centricon 30 (MWCO 100,000) was used following a native gel, which showed a band near 100,000. 


\section{Enzyme assay}

The activity of the extracted GDH was determined spectrophotometrically by measuring at $340 \mathrm{~nm}$ (using HITACHI model U-2000 double beam spectrophotometer) the initial rate of oxidation of NADH or NADPH or reduction of NAD or NADP at $30^{\circ} \mathrm{C}$. Before the assay, reaction mixtures were maintained at $30^{\circ} \mathrm{C}$ for 10 minutes. The standard amination reaction medium contained $200 \mathrm{mM}$ Tris- $\mathrm{HCl}$ ( $\mathrm{pH} 8.2$ for NADH- and 8.4 for NADPHmediated reactions, respectively), $50 \mathrm{mM}$ ammonium chloride, $4 \mathrm{mM} \alpha$-ketoglutarate and $18 \mathrm{mM} \mathrm{NADH}$ or $35 \mu \mathrm{M}$ NADPH. The deamination reaction medium used the same buffer concentration $(\mathrm{pH}$ 8.4 for NAD and 9.0 for NADP mediated reactions, respectively), $50 \mathrm{mM}$ L-glutamate, $40 \mu \mathrm{M}$ calcium ions $\left(\mathrm{Ca}^{2+}\right)$ and $6 \mathrm{mM}$ NAD or NADP. The coenzymes were adjusted to $\mathrm{pH} 7$ before use. All other substrates were prepared in assay buffer. Substrate saturation activities were assayed by varying the individual substrate and the initial velocities were recorded. Blank controls had individual substrates omitted. In assessing the effect of $\mathrm{pH}$ on enzyme activity, assay mixtures were prepared using $200 \mathrm{mM}$ Tris- $\mathrm{HCl}$ regulated to the $\mathrm{pH}$ of interest.
The effect of $140 \mu \mathrm{M}$ dimethylsulfoxide (DMSO) was used to establish the absence of phenols in the crude extract. Specific enzyme activity was expressed in units per mg protein. One unit is defined as the amount of enzyme required to form $1 \mu$ mole of co-enzyme (NADH/NADPH, NAD/NADP, respectively) per minute at $30{ }^{\circ} \mathrm{C}$. Protein content in the extracts was determined according to Peterson (1983). Assays were repeated at least twice and their mean results were recorded.

\section{RESULTS}

\section{GDH co-enzyme specificity}

The enzyme partially purified by Bis NAD precipitation and filtration (MWCO 100,000) exhibited NADH-, NADPH-, NAD- and NADPdependent activities with specific activities of 55.511 and 102.559 for the amination and 5625.499 and 490.389 for the deamination, respectively (Table 1). The activities with NAD as co-enzyme were in the order of 11.4-fold higher in the deamination and that of NADH was 1.8 -fold lower in the amination. The crude extract also exhibited NADH-, NADPH-, NAD- and NADP-dependent activities. However, NAD-dependent specific

Table 1. Purification of glutamate dehydrogenase: Shown values of protein concentration and enzyme activity are mean values of at least two determinations. The degree of purification was calculated as a ratio of the specific activities (units of enzyme activity/mg protein) before and after the purification procedures shown. Percentage recovery of the enzyme activities was corrected for the actual proportion of the initial tissue extract used in each purification step

\begin{tabular}{|c|c|c|c|c|c|c|c|}
\hline \multirow[t]{2}{*}{ Enzyme preparation } & \multirow[t]{2}{*}{$\begin{array}{l}\text { Volume } \\
(\mathrm{ml})\end{array}$} & \multirow[t]{2}{*}{$\begin{array}{l}\text { Total protein } \\
(\mathrm{mg})\end{array}$} & \multicolumn{5}{|c|}{$\begin{array}{l}\text { Enzyme activities, purification factor } \\
\text { and } \% \text { recovery }\end{array}$} \\
\hline & & & & TA & $\mathrm{SA} \quad \mathrm{OF}$ & $\mathrm{PP}$ (fold) & OR (\%) \\
\hline Crude extract & 650 & 163.345 & $\begin{array}{l}\text { NADH } \\
\text { NADPH } \\
\text { NAD } \\
\text { NADP }\end{array}$ & $\begin{array}{r}75.30 \\
333.71 \\
5066.80 \\
7515.34\end{array}$ & $\begin{array}{r}0.46 \\
2.04 \\
31.01 \\
46.00\end{array}$ & $\begin{array}{l}1 \\
1 \\
1 \\
1\end{array}$ & $\begin{array}{l}100 \\
100 \\
100 \\
100\end{array}$ \\
\hline $\begin{array}{l}75 \%\left(\mathrm{NH}_{4}\right)_{2} \mathrm{SO}_{4} \\
\text { precipitation and dialysis }\end{array}$ & 89 & 7.3069 & $\begin{array}{l}\text { NADH } \\
\text { NADPH } \\
\text { NAD } \\
\text { NADP }\end{array}$ & $\begin{array}{r}17.48 \\
111.13 \\
12587.18 \\
8596.06\end{array}$ & $\begin{array}{r}2.39 \\
15.20 \\
1722.64 \\
1176.43\end{array}$ & $\begin{array}{r}5.1 \\
7.4 \\
55.5 \\
25.5\end{array}$ & $\begin{array}{c}23.2 \\
33.3 \\
248.4 \\
114.38\end{array}$ \\
\hline $\begin{array}{l}\text { Bis-NAD }{ }^{+} \\
\text {precipitation, Cetricon } \\
100 \text { filtration and dialysis }\end{array}$ & 3 & 1.7232 & $\begin{array}{l}\text { NADH } \\
\text { NADPH } \\
\text { NAD } \\
\text { NADP }\end{array}$ & $\begin{array}{r}95.66 \\
176.73 \\
9693.86 \\
844.389\end{array}$ & $\begin{array}{r}55.51 \\
102.55 \\
5625.49 \\
490.01\end{array}$ & $\begin{array}{r}120.6 \\
50.2 \\
181.3 \\
10.6\end{array}$ & $\begin{array}{r}127.03 \\
52.56 \\
191.32 \\
11.23\end{array}$ \\
\hline
\end{tabular}

TA, total activity; SA, specific activity; OP, overall purification (fold); OR, overall recovery.

${ }^{+}$Bis-NAD $=\mathrm{N}_{2} \mathrm{~N}_{2}$-adipodihydrazido-bis-( $\mathrm{N}^{6}$-carbonylmenthl-NAD). 
activity was $33 \%$ lower than NADP-dependent activity, while NADPH-dependent activity was 4.4 higher than NADH- dependent activity.

The GDH was partially purified as the NADH, NADPH-, NAD- and NADP- dependent specific activity for the crude extract and the dialysed BisNAD product were about 120, 50, 180 and 10-fold purified, respectively. Enzyme recovery in the purification process was about 120,50, 190 and $10 \%$ for the NADH-, NADPH-, NAD- and NADPdependent enzymes, indicating that the crude extract contained some inhibitory factors for NADH- and NAD- dependent activities.

\section{Effects of calcium ions on the GDH activity}

The relationship between calcium ion concentration and NADH-, NADPH-, NAD- and NADP- influenced activity of GDH were examined (Fig.1). In the presence of $50 \mu \mathrm{M} \mathrm{Ca}^{2+}$ the NADPHdependent activity maximally increased by 2.4 -fold and any further increase of the concentration decreased the activity. The NADH-dependent activity gradually decreased with an increase in $\mathrm{Ca}^{2+}$ concentration (Fig 1a).

In the deamination reaction, at $40 \mu \mathrm{M} \mathrm{Ca}^{2+}$ the NAD-dependent activity was increased 3 -fold while further increase in the concentration decreased the activity. The NADP-dependent activity was increased 1.3 -fold at $25 \mu \mathrm{M} \mathrm{Ca}^{2+}$, but unlike NAD-GDH, further increase in $\mathrm{Ca}^{2+}$ was accompanied by an insignificant decrease until the $\mathrm{Ca}^{2+}$ was above $75 \mathrm{mM}$ (Fig. 1b).

\section{Optimal pH}

Amination for NADH-mediated activity was maximal at $\mathrm{pH} 8.1$ and for NADPH-mediated activity it was maximal at pH 8.4 (Fig. 2a). Towards the acidic values the profiles of both curves did not decline as steeply as towards the basic pH. Maximum deamination NADPdependent activity was at $\mathrm{pH}$ 9.0. Towards both acidic and basic $\mathrm{pH}$ values, the decline of the activities were steep. NAD-dependent deamination

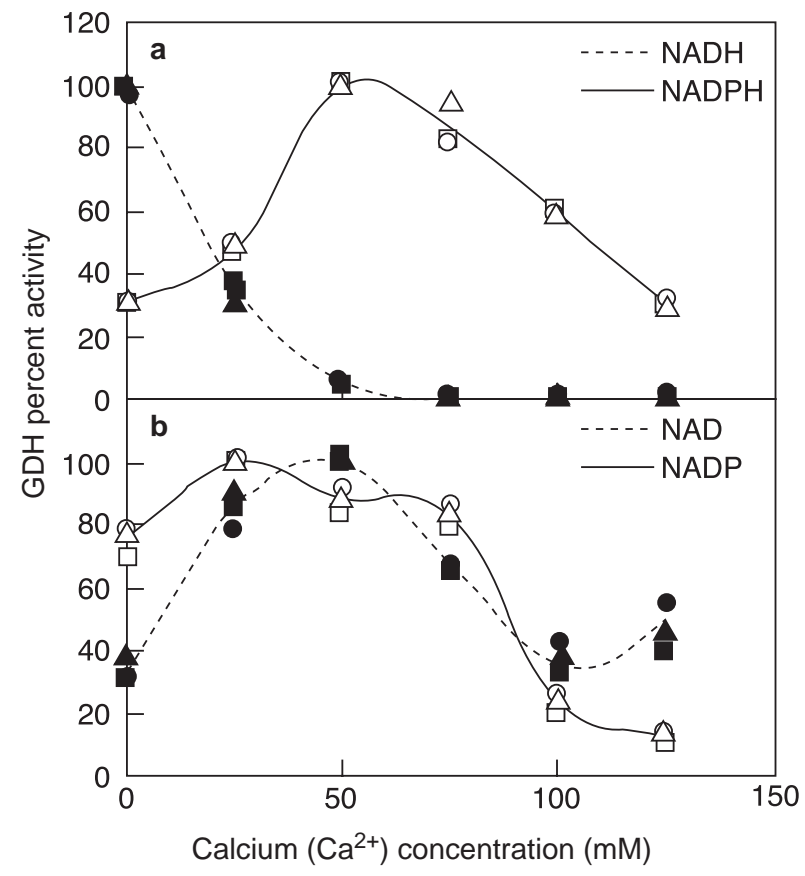

Fig. 1. Mean calcium ions ( $\mathrm{Ca}^{2+}$ ) activity profiles for NADPH-GDH (A) and NAD-GDH (B) from G. sordida as influenced by NADPH, NADH, NADP and NADP, respectively. Filled square, circle and triangle or their respective open symbols at each point along the profiles represent results for the three assays; mean values were used to generate the profiles. Standard amination and deamination reaction mixtures were used except for the $\left[\mathrm{Ca}^{2+}\right.$, which were varied as shown in the figures 
activity was maximal at $\mathrm{pH} 8.4$, but there was another small peak of activity at $\mathrm{pH} 9.4$. Between the $\mathrm{pH} 8.4$ and 9.4 peaks, the decline of activity was as steep as away from them.

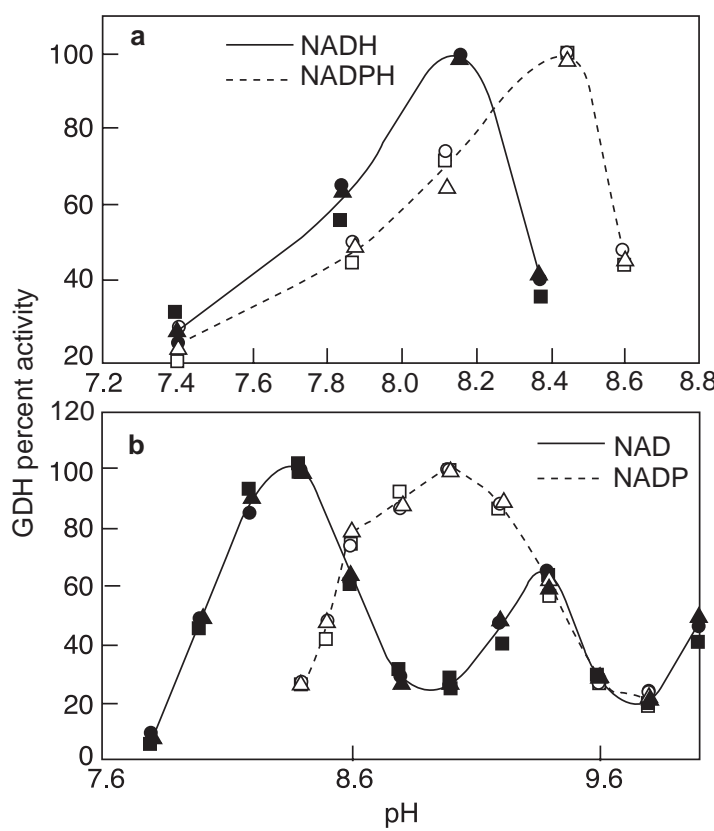

Fig. 2. Mean pH activity profiles for NADPH-GDH (a) and NAD-GDH (b) from Gracilaria sordida as influenced by NADPH, NADH, NADP and NADP, respectively. Filled square, circle and triangle or their respective open symbols at each point along the profiles represent results for the three assays; mean values were used to generate the profile. Standard amination and deamination reaction mixtures were used except for the $\mathrm{pH}$, which was varied as shown in the figures.

\section{Substrate saturation kinetics}

The substrate saturation curves were analysed by Lineweaver and Burk plots and $\mathrm{K}_{\mathrm{m}}$ values are presented in Table 2 and Fig. 3. All the $\mathrm{K}_{\mathrm{m}}$ s were
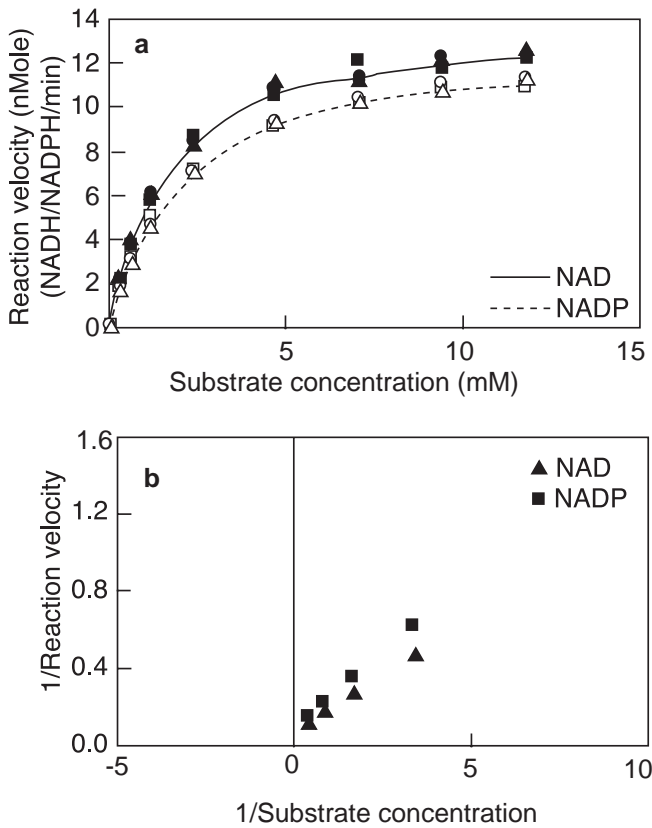

Fig. 3. Mean effect of L-glutamate concentration on the initial rate of NAD- influenced GDH catalysed reaction (a). Filled square, circle and triangle or their respective open symbols at each point along the curves represent results for the three assays; mean values were used to generate the curves. The reciprocal plot of the said mean enzyme rate is shown in (b) where the $x$ and $y$ intercepts were taken as $-1 / K_{m}$ and $1 / V_{\text {max }}$ respectively. $\mathrm{Km}$ for the different substrates in the NADH-, NADPH-, NAD- and NADP influenced activities are shown in Table 2 . In each case, respective standard amination or deamination reaction mixtures were used except for the substrate concentration, which was varied.

Table 2. Michaelis Menten constants for substrates of the enzyme GDH from Gracilaria sordida in its amination and deamination reactions under NADH/NADPH and NAD/NADP respectively. The constants were determined as shown for L-glutamate in Fig. 3.

\begin{tabular}{|c|c|c|c|c|c|}
\hline \multirow[b]{3}{*}{ Substrate } & \multirow{2}{*}{\multicolumn{2}{|c|}{$\frac{\text { Amination reaction }}{\mathrm{K}_{\mathrm{m}}(\text { in } \mathrm{mM})}$}} & \multirow{2}{*}{\multicolumn{3}{|c|}{$\frac{\text { Deamination reaction }}{\mathrm{K}_{\mathrm{m}}(\text { in } \mathrm{mM})}$}} \\
\hline & & & & & \\
\hline & NADH & $\mathrm{NADP}(\mathrm{P})^{+}$ & Substrate & NAD & NADP \\
\hline Ammonia & 3.610 & 3.077 & L-glutamate & 1.670 & 2.130 \\
\hline$\alpha$-ketoglutarate & 3.330 & 2.000 & NAD & 0.345 & - \\
\hline $\mathrm{NADH}$ & 0.00286 & - & NADP & - & 0.476 \\
\hline NADPH & - & 0.0033 & - & - & - \\
\hline
\end{tabular}

+at $50 \mathrm{mM} \mathrm{Ca}^{2+}$ 
below $3.6 \mathrm{mM}$. The affinity for glutamate (as shown by $\mathrm{K}_{\mathrm{m}}$ 1.670-2.130) were higher than ammonia (Km 3.077-3.610) and it was NADdependent activity that had the highest affinity for glutamate $(1.670 \mathrm{mM})$. In amination reactions, NADPH-dependent activity was $\left(\mathrm{K}_{\mathrm{m}} 3.077\right)$ higher than NADH- dependent activity $\left(\mathrm{K}_{\mathrm{m}} 3.610\right)$.

\section{Effect of the products of the reaction on the catalysis velocity}

L-Glutamate, NAD and NADP were added to the assay mixture during amination, and ammonia, $\alpha$ ketoglutarate, NADH and NADPH during deamination. The deamination products were more inhibitory to the catabolic reaction than the amination products were to the anobolic reaction (Fig. 4). Whereas the catabolic activities could not be detected in the presence of less than $1 \mathrm{mM}$ of its products, anabolic activities were even at $>1$ $\mathrm{mM}$ of its products.

\section{DISCUSSION}

Terrestrial plant glutamate dehydrogenases (GDH) may be mitochondrial (for deamination) or chloroplastic (for amination or amino acid synthesis) with NAD-GDH and NADPH-GDH dominating in the first and second organelle, respectively. Both enzymes have dual co-enzyme specificity to some extent. In the present study, both GDHs appear to be present in the crude extract and the semi-purified product (Table 1). In another red alga Porphyra yezoensis, NADPH-GDH was detected but NADH-GDH was not, and the

Fig. 4. Amination and deamination product activity profile of NADPH-GDH (A1-A2) and NAD-GDH (D1D3).

During deamination the influence of different concentrations of ammonia (NH4), $\alpha$-ketoglutarate (KG), NADH (NADH) and NADPH (NADPH) were measured when GDH was influenced by NAD (NADINF) or NADP (NADP-INF). In each case, respective standard amination or deamination reaction mixtures were used in the presence of the shown product concentration. Filled square, circle and triangle or their respective open symbols at each point along the profiles represent results for the three assays; mean values were used to generate the profiles
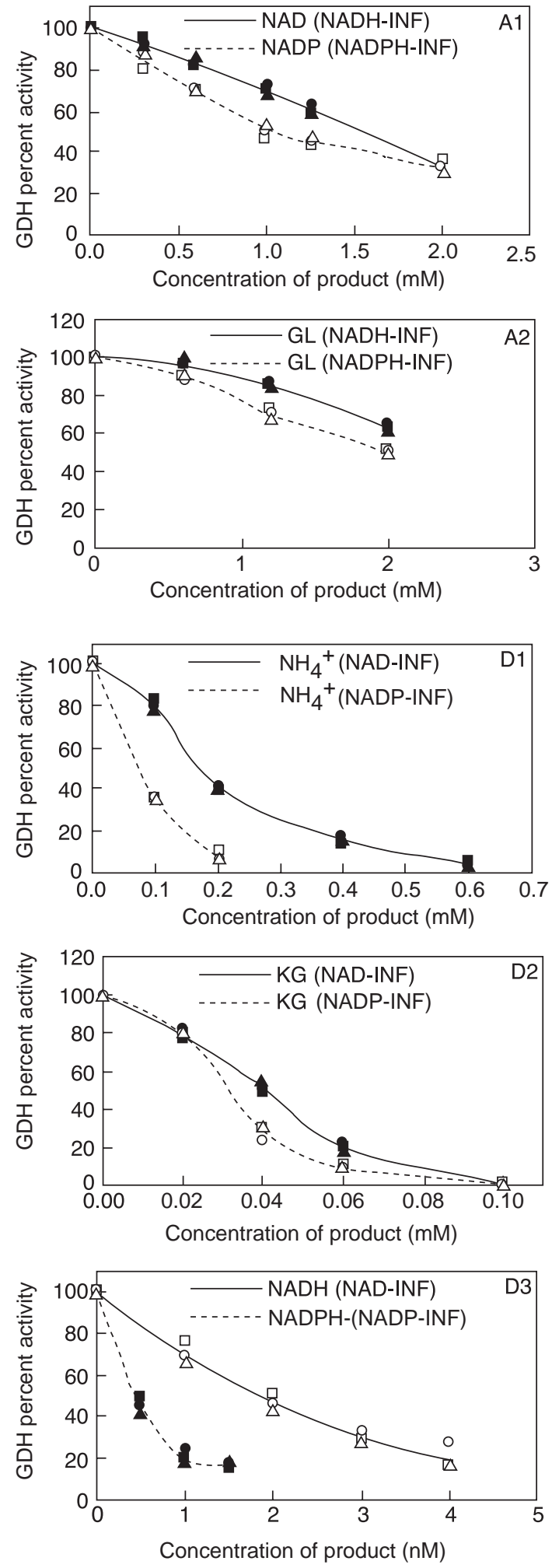
extracted NADPH-GDH had an insignificant NADH-dependent activity (Sato et al., 1984). The NAD-/NADP- and NADH-/NADPH- dependent activities reported in this study for the crude extract and the Bis-NAD product (in parentheses) were of the order of $1: 1.5(11: 1)$ and $1: 4.4(1: 1.8)$, respectively.

The shown NADH-/NADPH-dependent activities differ significantly from those reported for the green alga Caulerpa simpliciuscula where $\mathrm{NADH}-/ \mathrm{NADPH}$ - dependent activities in the crude extract and the purified enzyme were 1:9 and 1:75 respectively (Gayler \& Morgan, 1976). The $\mathrm{pH}$ optima for amination and deamination in this study were 8.2 and 8.4 under NADH- and NADPH- and 8.4 and 9 under NAD- and NADP-dependent activities, respectively. Although the shown optimum $\mathrm{pH}$ for NADP-dependent activity is closer to that of Porphyra yezoensis GDH (8.8), that for NADPH-dependent activity is much higher than that for Porphyra (pH 7.7) (Sato et al., 1984). It is possible that NAD-, NADP-, NADH- and NADPH-dependent activities vary with species and/or growth conditions. Growth in high ammonium or low nitrate media caused a large de novo synthesis of NADPH-dependent GDH in Chlorella (Ahmad \& Hallebust, 1984; Bascomb et al., 1987; Bascomb \& Schmidt, 1987). In the present study, NAD-GDH dominated despite growing $G$. sordida in ammonia.

The studies reported here have shown that both NAD- and NADP-dependent deamination activities were activated by calcium ions $\left(\mathrm{Ca}^{2+}\right)$. In the amination reactions, only the NADPHdependent reaction was activated. This is contrary to what has been reported from some terrestrial plant GDHs (Chou \& Splittstoesser, 1972; Joy, 1973; Furuhashi \& Takahashi, 1982) where amination but not deamination reaction appears to be activated by $\mathrm{Ca}^{2+}$.

A comparison of the affinity for substrates of previously characterised plant GDHs with the enzyme purified from G. sordida shows that the enzyme in the present study does not have an apparent affinity for ammonium ions as does that from green alga Caulerpa simpliciuscula $\left(\mathrm{K}_{\mathrm{m}} 0.4\right.$ 0.7, Gayler \& Morgan, 1976) and red alga Porphyra yezoensis (Sato et al,. 1984). The $\mathrm{K}_{\mathrm{m}}$ for ammonia reported in this study shows that GDH in G. sordida could be NAD-specific with a catabolic role as reported in higher plants (Lea \& Miflin, 2003 and references therein). Its anabolic role, e.g. assimilation of ammonia released during photorespiration and synthesis of N-rich transport compounds (Lea \& Miflin, 203) is not ruled out if ammonia concentration in mitochondria is in the range of 5-10 $\mu \mathrm{M}$ (Yamaya et al., 1984). Its molecular weight is so far not known, however its retention in a Cetricon 100 shows that its molecular weight is equal to or above 100,000. In Chlorella sorokiniana, mitochondrial and chloroplastic GDHs have been shown to be tetrameric and hexameric, respectively. Whereas the mitochondrial GDH had identical subunits with MW 45,000 each, the chloroplastic one had $\alpha$ - and $\beta$ isoenzymes with subunit MW of 55,500 and 53,000, respectively (Bascomb et al., 1987; Bascomb \& Schmidt, 1987; Meredith et al., 1978).

\section{CONCLUSION}

The glutamate dehydrogenases (GDHs) in Gracilaria sordida have an affinity for ammonia (Km 3.0-3.6). Establishing ammonia concentrations in algal mitochondria and chloroplasts is crucial to elucidating the role of GDH in the alga. However, assuming that ammonia concentration in $G$. sordida chloroplasts is in the same ranges as in higher plants (Lea \& Miflin, 2003), it is possible that GDHs in G. sordida play an insignificant role in glutamate formation. Their role could be that of facilitating a catabolic shunt in mitochondria if ammonia concentrations are similar to what is reported in corn shoot (Yamaya et al., 1984). Anabolic functions, e.g. the assimilation of ammonia released during photorespiration and synthesis of N-rich transport compounds are also possibilities (Lea \& Miflin, 2003).

Acknowledgements-This study was supported by a grant from the Swedish International Development Authority (Sida, SAREC) under the Tanzania-Sweden Bilateral Marine Science Program, for which I am grateful. I am also indebted to the Institute of Marine Sciences, University of Dar es Salaam for providing relevant facilities during the field studies. 


\section{REFERENCES}

Ahmad, I. \& Hallebust, J.A. (1984) Nitrogen metabolism of the marine macroalga Chlorella autotrophica. Plant Physiol. 76: 658-663.

Bascomb, N.F. \& Schmidt, R.R. (1987) Purification and partial kinetic and physical characterization of two chloroplastic-localized NADP-specific glutamate dehydrogenase isoenzymes and their preferential accumulation in Chlorella sorokiniana cells cultured at low or high ammonium levels. Plant Physiol. 83: 75-84.

Bascomb, N.F., Prunkard, D.E. \& Schmidt, R.R. (1987) Different rates of synthesis and degradation of two chloroplastic ammonium-inducible NADPspecific glutamate dehydrogenase isoenzymes during induction and deinduction in Chlorella sorokiniana cells. Plant Physiol. 83: 85-91.

Chou, K.H. \& Splittstoesser, W.E. (1972) Glutamate dehydrogenase from pumpkin cotyledons: characterization and isoenzymes. Plant Physiol. 49: $550-554$.

Cullimore, J.V. \& Sims, A.P. (1981a) Glutamine synthase of Chlamydomonas: its role in the control of nitrate assimilation. Planta 153: 18-24.

Cullimore, J.V. \& Sims, A.P. (1981b) Pathway of ammonia assimilation in illuminated and darkened Chlamydomonas reinhardii. Phytochemistry 20: 933-940.

Flygare, S., Griffin, T., Larsson, P. \& Mosbach, K. (1983) Affinity precipitation of dehydrogenases. Analytical Chemistry 133: 409-416.

Furuhashi, K. \& Takahashi, Y. (1982) Control of glutamate dehydrogenase from green tobacco callus mitochondria by $\mathrm{Ca}^{2+}$ and $\mathrm{pH}$. Plant Cell Physiol. 23: 179-184.

Gayler, K.R. \& Morgan, W.R. (1976) An NADPdependent glutamate dehydrogenase in chloroplasts from the marine green alga Caulerpa simpliciuscula. Plant Physiol. 58: 283-287.

Gronostajski, R.M., Yeung, A.T. \& Schmidt, P.R. (1978) Purification and properties of the inducible nicotinamide adenine dinucleotide phosphatespecific glutamate dehydrogenase from Chlorella sorokiniana. J. Bacteriol. 134: 621-628.

Jacobi, G. (1957) Enzyme des aminosaurestoffevechsels in Ulva lactuca. Transaminasen und aminosaure-dehydrogenasen. Planta 49: 561577.
Joy, K.D. (1973) Control of glutamate dehydrogenase from Pisum sativum roots. Phytochemistry 12: 1031-1040.

Lawrie, A.C., Codd, G.A. \& Stewart, W.D.P. (1976) The incorporation of nitrogen into product of recent photosynthesis in Anabaena cylindrica Lemm. Arch. Microbil. 107: 15-24.

Lea, P.L. \& Miflin, B.J. (2003) Glutamate synthase and the synthesis of glutamate in plants. Plant Physiology and Biochemistry 41: 503-676.

Lignell, A., Ekman, P. \& Pedersén, M. (1987) Cultivation technique for marine seaweeds allowing controlled and optimised conditions in the laboratory and on a pilot scale. Bot. Mar., 30: 417-424.

Meredith, M.J., Gronostajski, R.M. \& Shmidt, R.R. (1978) Physical and kinetic properties of the nicotinamide adenine dinucleotide-specific glutamate dehydrogenase purified from Chlorella sorokiniana. Plant Physiol. 61: 967-974.

Nisizawa, K., Anzai, H. \& Okugawa, Y. (1978) Glutamate dehydrogenase of a green alga, Bryopsis maxima. Jap. J. Phycol. 26: 145-150.

Peterson, G.L. (1983) Determination of total protein. Methods in Enzymology 91: 95-119.

Rigano, C., Rigano, V. M. Vona, V. \& Fuggi, A. (1979) Glutamine synthetase activity, ammonia assimilation and control of nitrate reduction in the unicellular red alga Cyanidium caldavium. Arch. Microbiol. 121: 117-120.

Shatlov, V.R. \& Kretovich, W.L. (1977) Glutamate dehydrogenases from Chlorella: forms regulation and properties. Mol. Cell Biochem. 15: 201-212.

Sato, M., Sato, Y. \& Tsuchiya, Y. (1975) Occurrence of glutamate dehydrogenase in purple laver, Porphyra yezoensis. Bull. Jap. Soc. Scient. Fish. 41: 337-341.

Sato, M., Sato, Y. \& Tsuchiya, Y. (1984) Glutamate dehydrogenase of Porphyra yezoensis. Hydrobiologia 116/117: 584-587.

Wolk, C.P., Thomas, J. \& Shaffer, P.W. (1976) Pathway of nitrogen metabolism after fixation of ${ }^{13} \mathrm{~N}$ labelled nitrogen gas by the cyanobacterium Anabaena cylindrica. J. Biol. Chem. 251: 50275034.

Yamaya, T., Oaks, A. \& Matumoto, H. (1984) Characteristics of glutamate dehydrogenase in mitochondria prepared from corn shoots. Plant Physiology 76: 1009-1013. 